\title{
Four Neuroendocrine Tumor Types and Neuroendocrine Carcinoma of the Duodenum: Analysis of 203 Cases
}

\author{
Alessandro Vanoli ${ }^{a}$ Stefano La Rosa ${ }^{b}$ Catherine Klersy ${ }^{c}$ Federica Grillo ${ }^{d}$ \\ Luca Albarello $^{\text {e }}$ Frediano Inzani $^{f}$ Roberta Maragliano ${ }^{g}$ Rachele Manca ${ }^{a}$ \\ Ombretta Luinetti $^{\mathrm{a}}$ Massimo Milione ${ }^{\mathrm{h}}$ Claudio Doglioni ${ }^{\mathrm{e}}$ Guido Rindi ${ }^{\mathrm{f}}$ \\ Carlo Capella ${ }^{9}$ Enrico Solcia ${ }^{a}$
}

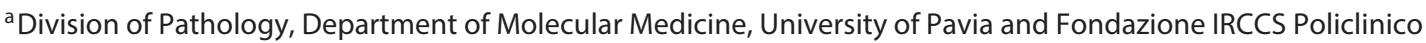
San Matteo, Pavia, b Department of Pathology, Ospedale di Circolo, Varese, ' Unit of Biometry and Clinical Epidemiology Service, Fondazione IRCCS Policlinico San Matteo, Pavia, dPathology Unit, Department of Surgical and Diagnostic Sciences (DISC), University of Genoa, Genoa, e Department of Pathology, San Raffaele Hospital, Milan, ${ }^{\mathrm{f}}$ Institute of Anatomic Pathology, Fondazione Policlinico Universitario A. Gemelli, Università Cattolica del Sacro Cuore, European NeuroEndocrine Tumor Society (ENETS) Center of Excellence for the Diagnosis and Cure of Neuroendocrine Tumor Patients, Rome, ${ }^{9}$ Department of Surgical and Morphological Sciences, University of Insubria, Varese, and h Anatomic Pathology, Department of Pathology and Laboratory Medicine, IRCCS Foundation National Cancer Institute, Milan, Italy

\section{Key Words}

Ampulla $\cdot$ Disease-specific survival $\cdot$ Duodenum $\cdot$ Histotypes . Hormones · Neuroendocrine neoplasms

\begin{abstract}
Background: Several types of neuroendocrine neoplasms (NENs) have been described in the duodenal tract, from lowgrade tumors (NETs) to high-grade neuroendocrine carcinomas (NECs). A comprehensive analysis of histology, hormonal profile and prognostic parameters of a sufficiently large duodenal NEN series to cover all main kinds of neoplasms is however lacking. Methods: We collected a retrospective series of 203 duodenal wall and ampullary region NENs, from six specialized endocrine pathology centers. All were characterized histopathologically and histochemically, and 190 were followed for a median of 9 years. Results: Twenty-sev-
\end{abstract}

en poorly differentiated NECs, mostly from the ampullary region, were identified and shown to lead to patient demise in a median of 10 months. Among 176 NETs, four subtypes were characterized, including 20 gastrinomas, 37 ampullary-type somatostatin-producing NETs (ASTs), 12 gangliocytic paragangliomas (GPs) and 106 nonfunctioning NETs (nfNETs). ASTs and GPs were mostly localized in the ampullary/periampullary region, while gastrinomas and nfNETs were mainly from the proximal duodenum. ASTs and gastrinomas showed high rates of local infiltration (especially lymphoinvasion and deep duodenal wall/pancreatic tissue invasion) and lymph node metastasis, while nfNETs had significantly lower and more size-dependent local invasive potential. Disease-specific survival differed significantly between NETs and NECs, though not among NET subtypes. NET cases with distant metastases $(n=23)$ were significantly associated with larger size, higher proliferative grade, lympho-

\section{KARGER}

(c) 2016 S. Karger AG, Basel

E-Mail karger@karger.com

www.karger.com/nen
Dr. Alessandro Vanoli

Division of Pathology, Department of Molecular Medicine

University of Pavia and Fondazione IRCCS Policlinico San Matteo

Via Forlanini 14, IT-27100 Pavia (Italy)

E-Mail ale.vanol@virgilio.it 
vascular invasion, deep invasion and local lymph node metastasis. Conclusion: Our careful analysis of a large series of duodenal NENs identified five histologically and prognostically different histotypes of potential clinical relevance.

(c) 2016 S. Karger AG, Basel

\section{Introduction}

The manifold population of neuroendocrine neoplasms (NENs) arising in the duodenal mucosa and ampullary region has been investigated in several papers, leading to the characterization of various tumor entities according to histological structure, hormonal expression, clinical profile, genetic background and/or patient outcome [1-7]. Most were low-grade tumors, ranging from reportedly self-limiting gangliocytic paragangliomas (GPs) to a variety of well-differentiated epithelial neuroendocrine tumors (NETs). This latter category comprised clinically silent or endocrinally active (such as gastrinomas) neoplasms of the duodenum as well as nonfunctioning, somatostatin cell tumors (often called 'somatostatinomas' despite their usual lack of clinically relevant signs of endocrine hyperfunction), commonly localized in the ampullary region and often causing biliary or pancreatic duct obstruction and regional lymph node (LN) metastases. A minority of tumors arose in a genetic background, such as gastrinomas in multiple endocrine neoplasia type 1 (MEN1) syndrome and somatostatin cell tumors in type 1 neurofibromatosis [4-6]. In addition to these differentiated, grade 1 or 2, NETs, a few high-grade (grade 3 ) neuroendocrine carcinomas (NECs) have also been reported $[8,9]$.

Given the relative rarity of such neoplasms, problems still exist concerning the identification of histotypes with well-defined pathological as well as clinical profiles, the understanding of their natural history and the development of reliable prognostic criteria. In particular, the following points deserve further investigation: (1) Does the type of hormone(s) expressed at the cellular level or the associated hyperfunctional syndrome independently predict tumor behavior? (2) Do proliferative grading or locally invasive microscopic pattern reliably predict tumor behavior? (3) Does the site of origin (e.g. ampullary region vs. the remaining duodenal wall) influence tumor type and/or prognosis?

A comprehensive analysis of hormone profiles, cytological features, histological structural and invasive patterns, proliferative grade, topography, stage and outcome of a sufficiently large case series to appropriately cover all tumor types has, up until now, been lacking. In this paper, a series of 203 duodenal cases, collected from 6 specialized endocrine pathology centers in Italy, were investigated and followed for a median of 9 years. Up to five tumor types with distinctive pathological and clinical profiles were characterized.

\section{Materials and Methods}

A total of 245 neoplasms from the duodenal tract and ampullary region diagnosed between 1980 and 2015 as 'differentiated (neuro)endocrine tumor', 'carcinoid', 'gastrinoma', 'somatostatinoma', 'gangliocytic paraganglioma' or 'poorly differentiated endocrine carcinoma (pdEC)' or '(neuro)endocrine carcinoma' were retrieved from the Endocrine Tumor Registers set up at the Pathology Departments of Pavia, Varese and Genova Universities, and Catholic University of Rome, and from the Neuroendocrine Pathology Databases of San Raffaele Hospital and 'Istituto Nazionale dei Tumori' Hospital in Milan. In 224 cases, available tissue was suitable for accurate histopathological and immunohistochemical reinvestigation. Pertinent clinical, endoscopic, radiological and laboratory data as well as follow-up information were obtained from clinical and follow-up records, local tumor registries and interviews with family doctors. Appropriate characterization was possible in 203 cases, and these were all considered for the present study. An overall median follow-up of 108 months (interquartile range: $50-181$ months) was recorded. Ten patients were lost to follow-up and 3 died during, or shortly after, surgery.

The study was performed in agreement with the clinical standards laid down in the 1975 Declaration of Helsinki and its revision in 1983, and has been approved by the Ethical Committee of the Ospedale di Circolo, Varese, Italy (No. 0008465).

Tissue from surgical resection was available in 147 cases and from endoscopically removed tumors in 56 cases (mostly well-differentiated, intramucosal to submucosal tumors). In surgical cases, TNM tumor stage was ascertained on histologically diagnosed surgical specimens, while for endoscopic cases, endoscopy findings, endoscopic ultrasonography, CT, PET or nuclear magnetic resonance imaging were also considered. LN status was unavailable at diagnosis in 9 cases, 8 of which were NECs, 4 with distant metastases at diagnosis and the remaining 3 became metastatic during the follow-up.

\section{Pathological Characterization}

All 203 neoplasms, of which a minority had previously been investigated [4], were studied for the following parameters: number of mitoses per 10 high power fields (HPF), lymphovascular invasion, tumor size, level of duodenal wall invasion, involvement of pancreas and periduodenal tissues, local LN/distant metastases, including all parameters required to fulfill the criteria of the WHO classification [10], the AJCC [11] and the ENETS [12] staging systems. In our series, no differences between the AJCC and ENETS systems were observed as all ampullary cases showing duodenal wall invasion were also $>1 \mathrm{~cm}$ in size, thus fitting into the T2 stage according to both systems. Therefore, the ENETS staging system was used for statistical analysis in this study. 


\section{Immunohistochemistry}

Immunohistochemical tests were performed for chromogranin A (monoclonal, clone LK2H10; Ventana, Tucson, Ariz., USA), synaptophysin (monoclonal, clone snp88; BioGenex Laboratories, San Ramon, Calif., USA) and Ki67 (monoclonal, clone MIB1; Dako, Carpinteria, Calif., USA) in all cases. Immunostainings for gastrin (polyclonal, Dako), somatostatin (polyclonal, Dako), serotonin (polyclonal; Novocastra, Newcastle, UK) and pancreatic polypeptide (PP, polyclonal; Peninsula Laboratories, Belmont, Calif., USA) were performed in NETs. Somatostatin receptor 2A (SSR2A) (monoclonal, clone UMB1; Abcam, Cambridge, UK), somatostatin receptor 5 (SSR5) (monoclonal, clone UMB4; Abcam), MUC1 (monoclonal, clone Ma695; Novocastra) and cytokeratin 7 (monoclonal, clone SP52; Ventana) were performed in ampullary-type somatostatin-producing tumors (ASTs) and a comparable number of (non-AST) NETs. In selected cases, immunohistochemical staining for insulin (monoclonal, clone AE9D6, BioGenex Laboratories) was tested. Somatostatin receptor expression was assessed with the scoring system proposed by Volante et al. [13]; only score 2 and 3 neoplasms were regarded as positive.

\section{Differentiation and Grade}

In general, well and poorly differentiated NENs were easily distinguished on morphological grounds $[10,14]$. Poorly differentiated NECs were characterized by poorly formed, large trabeculae and solid nests or diffuse sheets of anaplastic, round to spindle, small to intermediate or large cells, frequently showing multiple necrotic foci, brisk apoptotic activity and crush artifacts. Differentiated NETs showed well-defined trabecular, solid nests, microlobular, paraganglioid or 'pseudoglandular' (with tubular or acinar structures more or less abundantly scattered inside the tumor) growth patterns. Proliferative grade was assigned based on the mitotic and the Ki67 index. The Ki67 proliferative index was expressed as a percentage value corresponding to the count of Ki67positive nuclei in 2,000 tumor cells performed in areas of the highest immunostaining. G1 proliferative grade tumors were those with $<2$ mitoses $/ 10 \mathrm{HPFs}$ and $<2.5 \% \mathrm{Ki} 67$ index. G2 tumors were those with 2-20 mitoses/10 HPFs or 2.5-20.0\% Ki67 index [15]. Proliferative grade 3 neoplasms had $>20$ mitoses/10 HPFs and/or $>20.0 \%$ Ki67.

All tumor samples were reviewed by 2 surgical pathologists specialized in neuroendocrine pathology (E.S. and A.V.). In all cases, duodenal involvement by a pancreatic NEN was excluded.

\section{Statistical Analysis}

This is a longitudinal retrospective study. The follow-up extended from the date of surgery or endoscopy to the date of death or last follow-up. Descriptive statistics were computed as median and 25th-75th percentiles for continuous variables and as counts and percentage for categorical variables. Median follow-up and its interquartile range (25th-75th) were computed by means of the inverse Kaplan-Meier method. The Kruskall-Wallis test and Fisher's exact test were used to compare continuous and categorical variables, respectively, between types of neoplasms. The MannWhitney $U$ test was used to compare size between patients with and without LN metastases. Logistic regression was used to assess the association of a series of tumor characteristics and the presence of local metastases. Odds ratios and 95\% confidence intervals (CI) were computed. Receiver operating characteristic (ROC) curve analysis was performed to identify the optimal cutoff for size. Sensitivity, specificity, area under the ROC curve and 95\% CI were computed.

Cumulative survival was plotted according to the Kaplan-Meier method. The association between candidate prognostic factors and tumor death was estimated by means of Cox regression. All estimates were adjusted for age and stage in a multivariable model. Hazard ratios (HR) and their 95\% CI were computed. The proportional hazard assumption was tested based on Schoenfeld residuals. Death rates per 100 person-years $(95 \% \mathrm{CI})$ were also computed as summary measures. A two-sided $p$ value $<0.05$ was considered statistically significant. For post hoc comparisons, Bonferroni correction applied. Stata 14 (StataCorp, College Station, Tex., USA) was used for computation.

\section{Results}

\section{NECs and NETs}

The whole patient series of 203 cases, composed of 88 females and 115 males, median age 62 (25th-75th, 49-70 years), were first classified as NETs (176 cases), or grade 3 NECs (27 cases), based on the general morphological and proliferative criteria recommended by the $\mathrm{WHO}$ 2010 classification.

All 27 NECs had a Ki67 index of $>20 \%$ (and 21 had $>50 \%$ ), thus fulfilling at least one major requirement for grade 3 attribution. Twenty-one cases showed $>20 \mathrm{mi}$ totic figures/10 HPFs, while 5 cases showed a discrepancy between mitotic and proliferative indexes (Ki67 $>20 \%$ but $<20$ mitoses/10 HPFs). All 27 NECs showed poorly differentiated morphology throughout or in a predominant part of neoplastic tissue, 11 of small and 16 of large cell type (fig. 1a, b), often coupled with necrosis. Three cases of mixed NEC and adenocarcinoma, with predominance of the former component, were included in the NEC group. We obtained no evidence, by histological analysis of recurrent, invasive or metastatic tissue, of direct progression of a differentiated NET to a poorly differentiated, small- or large-cell NEC.

Of the 176 NETs, 31 had a Ki67 index of 2.5-20\% and 16 had 2-20 mitoses/10 HPFs, the agreed limits for proliferative grade 2 . In all, 36 NETs were within such limits, either due to Ki67 index alone (20 cases), or to mitotic index alone ( 5 cases) or to both ( 11 cases), and were thus classified as grade 2 , whereas the remaining 140 cases had both a Ki67 index of $<2.5 \%$ and $<2$ mitoses/10 HPFs, i.e. grade 1. All NETs showed a differentiated histological structure of trabecular, microlobular, solid nests and/or gland-forming type (fig. 1c, d). No well-differentiated NETs with a Ki67 index $>20 \%$ or $>20$ mitoses/10 HPFs were detected. 


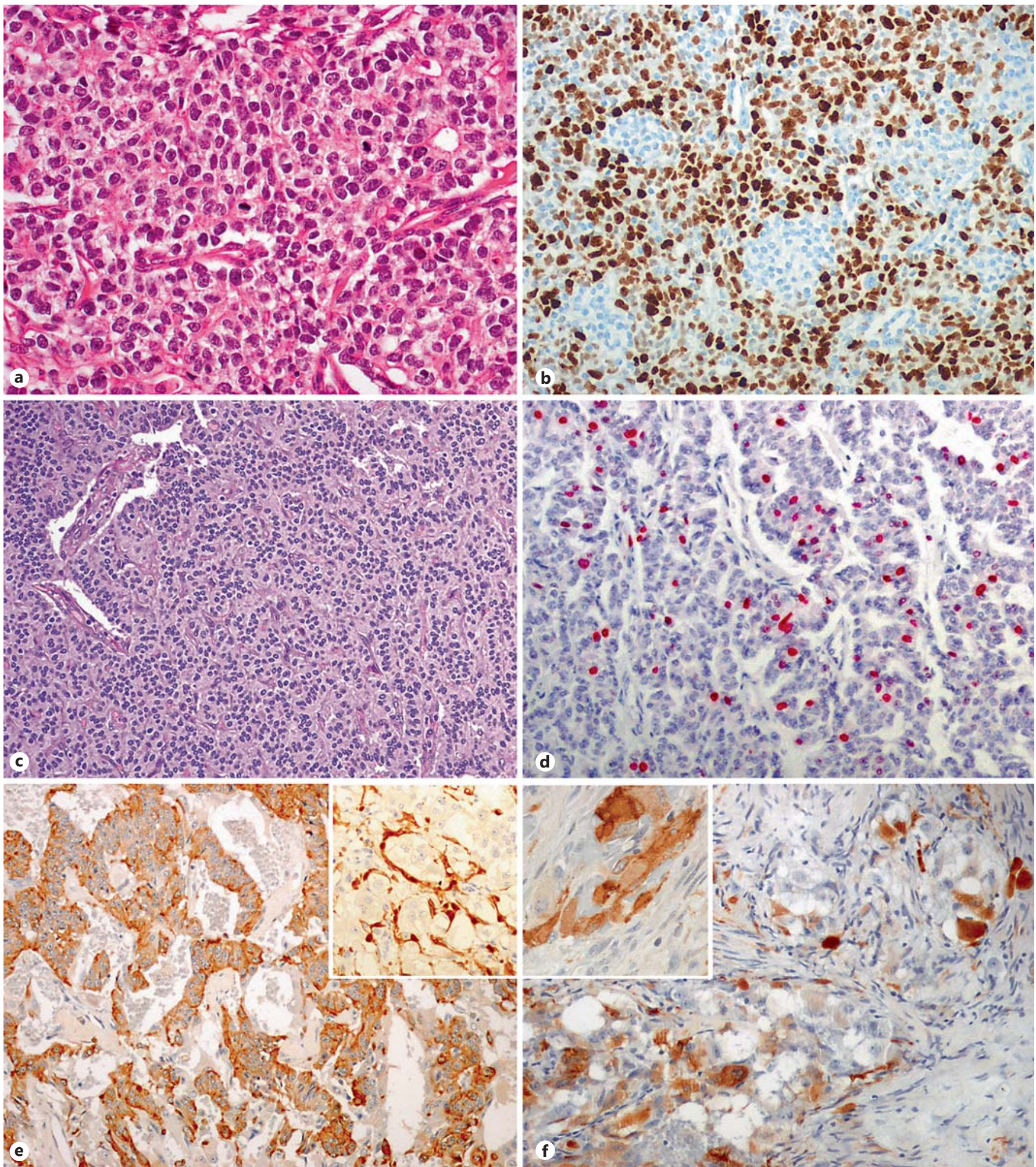

Fig. 1. Large-cell (a; hematoxylin-eosin, $\times 250)$ and small-cell (b; Ki67, hematoxylin, $\times 100$ ) poorly differentiated NECs. Grade 1 (c; hematoxylin-eosin, $\times 100)$ and grade $2(\mathbf{d}$; Ki67, with fast red as chromogen, $\times 150$ ) NETs of trabecular structure, nonfunctioning. e, f GPs. PP-reactive paragangliomatous $(\mathbf{e} ; \times 100)$, S100-reactive spindle cell (inset to e, $\times 200$ ) and somatostatin-reactive ganglionlike cell $(\mathbf{f} ; \times 150)$ components in a GP. In the inset to $\mathbf{f}(\times 400)$, somatostatin-reactive ganglion-like cells in a GP LN metastasis. 
Table 1. Types and clinicopathological patterns of neoplasms investigated

\begin{tabular}{|c|c|c|c|c|c|c|c|c|c|c|}
\hline & \multirow[t]{2}{*}{$\mathrm{All}^{\mathrm{a}}$} & \multirow[t]{2}{*}{ NEC } & \multirow[t]{2}{*}{$\mathrm{NET}^{\mathrm{a}}$} & \multirow{2}{*}{$\begin{array}{l}\text { NEC vs. } \\
\text { NET, } \\
\text { p value }\end{array}$} & \multicolumn{4}{|c|}{ Four NET subtypes } & \multirow{2}{*}{$\begin{array}{l}\text { Sub- } \\
\text { types } \\
\text { overall, } \\
\text { p value }\end{array}$} & \multirow{2}{*}{$\begin{array}{l}\text { Significant differences } \\
\text { among subtypes, } \\
\text { p value }\end{array}$} \\
\hline & & & & & GAS & nfNET & AST & GP & & \\
\hline Age, years & $62(49-70)$ & $66(58-71)$ & $60(48-70)$ & 0.141 & $47(38-64)$ & $64(54-73)$ & $50(43-61)$ & $58(46-71)$ & $<0.001$ & $\begin{array}{l}\text { GAS vs. nfNET: } 0.001 \\
\text { nfNET vs. AST: }<0.001\end{array}$ \\
\hline$\overline{\text { Site }}$ & & & & $<0.001$ & & & & & $<0.001$ & $\begin{array}{l}\text { GAS vs. AST: }<0.001 \\
\text { GAS vs. GP: }<0.001 \\
\text { nfNET vs. AST: }<0.001 \\
\text { nfNET vs. GP: }<0.001\end{array}$ \\
\hline Duodenum I & $97(49)$ & 0 & $97(56)$ & & $15(79)$ & $81(76)$ & $1(3)$ & 0 & & \\
\hline Duodenum II & $19(9)$ & $1(4)$ & $18(10)$ & & $3(16)$ & $10(10)$ & $1(3)$ & $3(25)$ & & \\
\hline Ampullary region & $77(39)$ & $22(85)$ & $55(32)$ & & $1(5)$ & $12(11)$ & $34(94)$ & $8(67)$ & & \\
\hline Duodenum III or IV & $7(3)$ & $3(11)$ & $4(2)$ & & 0 & $3(3)$ & 0 & $1(8)$ & & \\
\hline Size, $\mathrm{cm}$ & $1.00(0.50-2)$ & $2.50(1.7-3.5)$ & $1.00(0.4-2.0)$ & $<0.001$ & $0.75(0.5-1.2)$ & $0.60(0.3-1.3)$ & $2.50(1.5-3.0)$ & $2.00(1.3-2.5)$ & $<0.001$ & $\begin{array}{l}\text { GAS vs. AST: }<0.001 \\
\text { nfNET vs. AST: }<0.001 \\
\text { GAS vs. GP: } 0.001 \\
\text { nfNET vs. GP: }<0.001\end{array}$ \\
\hline $\begin{array}{l}\text { Invasion beyond the } \\
\text { submucosa }\end{array}$ & $82(43)$ & $18(90)$ & $64(38)$ & $<0.001$ & $9(47)$ & $24(23)$ & $24(67)$ & $7(58)$ & $<0.001$ & nfNET vs. AST: $<0.001$ \\
\hline
\end{tabular}

Data are presented as $\mathrm{n}(\%)$ or median (interquartile range). Duodenum I = First part of the duodenum; duodenum II = second part of the duodenum (ampullary region excluded); duodenum III or IV = third or fourth part of the duodenum; GAS = gastrinoma. ${ }^{\text {a }}$ Including the insulinoma.

Table 2. Metastatic profile and stage according to neoplasm type and size

\begin{tabular}{lccll}
\hline & $\begin{array}{l}\text { Available } \\
\text { cases }\end{array}$ & LN met. & $\begin{array}{l}\text { Distant } \\
\text { met. }\end{array}$ & $\begin{array}{l}\text { Stage III + } \\
\text { IV }\end{array}$ \\
\hline NEC & 23 & $15(79)^{\mathrm{a}, \mathrm{b}}$ & $12(52)^{\mathrm{a}}$ & $21(91)^{\mathrm{a}}$ \\
NET & 175 & $52(30)$ & $13(7)$ & $54(31)$ \\
GAS & 20 & $10(50)^{\mathrm{c}}$ & $2(10)$ & $10(50)^{\mathrm{c}}$ \\
nfNET & 105 & $19(18)$ & $8(8)$ & $20(19)$ \\
$\quad<1 \mathrm{~cm}$ & 66 & $3(4)^{\mathrm{d}}$ & $0(0)^{\mathrm{d}}$ & $3(4)^{\mathrm{d}}$ \\
1 to $<2 \mathrm{~cm}$ & 21 & $6(29)$ & $1(5)$ & $7(33)$ \\
$\geq 2 \mathrm{~cm}$ & 18 & $10(56)$ & $7(39)$ & $10(56)$ \\
AST & 37 & $20(54)^{\mathrm{e}}$ & $3(8)$ & $21(57)$ \\
$<2 \mathrm{~cm}$ & 14 & $4(29)^{\mathrm{f}}$ & $1(7)$ & $5(36)$ \\
$\geq 2 \mathrm{~cm}$ & 23 & $16(70)$ & $2(9)$ & $16(70)$ \\
GP & 12 & $3(25)$ & $0(0)$ & $3(25)$ \\
& & & &
\end{tabular}

Data are presented as $\mathrm{n}$ or $\mathrm{n}(\%)$. GAS = Gastrinoma; met. = metastases. Size proved informative only for nfNET and AST. ${ }^{a} \mathrm{p}<0.001$ vs. NET; ${ }^{b}$ lymph node status not available at diagnosis in 4 of the 23 NEC cases; ${ }^{c} p=0.007$ vs. nfNET; ${ }^{d} p<0.001$ vs. other nfNET size groups; ${ }^{\mathrm{e}} \mathrm{p}<0.001$ vs. $n f N E T ;{ }^{\mathrm{f}} \mathrm{p}<0.015 \mathrm{vs} . \geq 2 \mathrm{~cm}$ AST group.
When NECs were compared with NETs as a whole or with grade 1 NETs, highly significant differences (Fisher exact test $\mathrm{p}<0.001$ ) were seen in terms of site, size, lymphovascular invasion, duodenal wall invasion beyond submucosa, local LN and distant metastases, as well as stage (tables 1,2). NECs showed significant differences compared to grade 2 NETs in terms of site $(p=0.002)$, size $(\mathrm{p}=0.049)$ and distant metastases $(\mathrm{p}=0.021)$. Grade 2 NETs showed significant differences compared to corresponding grade 1 cases in terms of size, lymphovascular invasion, deep duodenal wall invasion and LN metastases (for all variables, $\mathrm{p}<0.001$ ), as well as for distant metastases $(p=0.005)$. Among NETs, grade 2 proliferative index was significantly associated with LN metastases with high specificity ( $88 \%, 95 \%$ CI $87-93)$, low sensitivity $(40 \%, 27-55)$ and moderate ROC area $(0.64,0.57-$ $0.71)$. Lymphovascular invasion, on the other hand, showed better sensitivity $(72 \%, 58-84)$, fairly good specificity $(78 \%, 70-86)$ and improved ROC area $(0.75,0.68-$ $0.83)$.

\section{NET Subtypes}

Based on the histological, histochemical, functional and topographic criteria, four subtypes were identified in the large NET population (176 cases; tables 1,2). 
Gangliocytic Paragangliomas

Twelve GPs were easily separated from the remaining 164 NETs owing to their peculiar admixture of an epithelial endocrine (paraganglioid) component, mostly expressing PP and somatostatin, with gangliocytic and spindle cell components better stained by synaptophysin or somatostatin and by S-100 antibodies, respectively (fig. 1e, f). Most GPs (11/12) showed grade 1 proliferative and cytological patterns, despite an infiltrative pattern involving the muscolaris propria in 7 cases. Three cases showed local LN metastases, where, in addition to the predominant epithelial component, the gangliocytic and spindle cell components were also detected (fig. 1f). One of the 3 metastastic cases had a large $(6 \mathrm{~cm})$, grade 2 , primary neoplasm, deeply invasive of the muscolaris propria, which recurred after surgery and caused the patient's death 4 years later.

\section{Gastrinomas}

Among the 164 purely epithelial NETs, 21 were associated with clinical signs of endocrine hyperfunction, in addition to histochemical and/or immunochemical evidence of pertinent hormone hypersecretion in the tumor tissue or blood (hyperfunctioning NETs), while 143 cases lacked clinically relevant signs of endocrine hyperfunction. In addition to a single insulinoma, reported elsewhere [16], 20 cases showed signs of gastric acid hypersecretion, acidopeptic gland hypertrophy with parietal as well as ECL cell hypertrophy and hyperplasia, peptic ulcer disease and/or reflux esophagitis and were diagnosed as gastrinomas. Seven cases were MEN1 syndrome associated and, of these, 5/7 (71\%) neoplasms were metastatic to local LNs, compared to less than half $(5 / 13,38 \%)$ of the sporadic cases. Most tumors were characterized by welldefined gyriform trabeculae, often coupled with vascular pseudorosettes, and were proliferative grade 1 (fig. $2 \mathrm{a}$ ).

\section{Ampullary-Type Somatostatin-Producing Tumors}

Among the remaining 143 NETs, 37 formed a welldefined group characterized by extensive reactivity for somatostatin (involving $60-100 \%$, mean $90 \%$, of tumor cells), strong preference for the ampullary-papillary re-

Fig. 2. a Gastrin-immunoreactive NET with gyriform trabeculae and vascular stroma (pseudorosettes), associated with ZollingerEllison syndrome (gastrinoma). $\times 150$. ASTs with tubules and psammoma bodies, diffusely and uniformly immunoreactive for somatostatin $(\mathbf{b} ; \times 100)$, invasive of the muscularis propria (c; $\times 100)$ and showing membranous immunostaining for type 5 so-

Duodenal Neuroendocrine Neoplasms gion (34 out of 36 cases ascertained, including 4 cases from the minor papilla), presence of tubular-acinar structures, with or without intraluminal psammoma bodies, in a moderately defined solid or trabecular background of fairly large cells with abundant granular eosinophilic cytoplasm (fig. 2b, c). These ASTs, 4 of which in the background of type 1 neurofibromatosis, showed, in spite of a predominance of grade 1 proliferative index (24 cases), frequent microinvasion (especially lymphoinvasion, 28 cases), high local LN metastatic rate (54\%) and frequent signs of pancreatobiliary duct obstruction. Lack of cell membrane reactivity of tumor cells for somatostatin receptor type 2A (as found in 25/29 cases investigated, two of the 4 exceptions focally showing receptor type $2 \mathrm{~A}$ reactive gastrin cells in addition to extensive somatostatin expressing cells unreactive for type $2 \mathrm{~A}$ receptor), coupled with retention of the type 5 receptor membrane reactivity (18/22), was also noteworthy in ASTs (fig. 2d, e). In contrast, most other NETs expressed both type 2A (57/64 cases tested) and type $5(39 / 48)$ somatostatin receptors (fig. 2f).

Most ASTs showed more or less extensive reactivity for the ampullary and pancreatobiliary markers MUC1 (31/32 compared to $25 / 70$ of other NETs; fig. $2 \mathrm{~g}$ ) and cytokeratin 7 (11/17, compared to $4 / 19$ of other NETs; fig. 3a). Interestingly, scattered somatostatin cells were observed in the adjacent normal ampullary epithelium, while in some AST cases, these cells formed linear or micronodular growths budding into the surrounding stroma (fig. 3b).

\section{Ordinary Nonfunctioning NETs}

The remaining 106 nonfunctioning NETs (nfNETs) showed, besides prominent staining with general neuroendocrine markers like chromogranin A and synaptophysin, reactivity to a variety of hormones (fig. 3c-e), either alone or variably admixed. Gastrin cells were often the dominant cell type in such NETs and were at any rate present in $69 \%$ of cases, followed by somatostatin (33\%) or serotonin cells and, though rarely, by PP and insulin cells. This overwhelming group of ordinary nfNETs was predominantly localized in the first part of the duode-

matostatin receptor $(\mathbf{e} ; \times 400)$, though lacking reactivity for type $2 \mathrm{~A}$ somatostatin receptor $(\mathbf{d} ; \times 400)$, to be compared with intense membranous staining for type $2 \mathrm{~A}$ somatostatin receptor in a gastrinoma $(\mathbf{f} ; \times 200)$. g MUC1-reactive AST; note the intense staining of tubule luminal surface, in addition to moderate cytoplasmic staining of some tumor cells. $\times 400$.

(For figure see next page.)

Neuroendocrinology 2017;104:112-125 117 

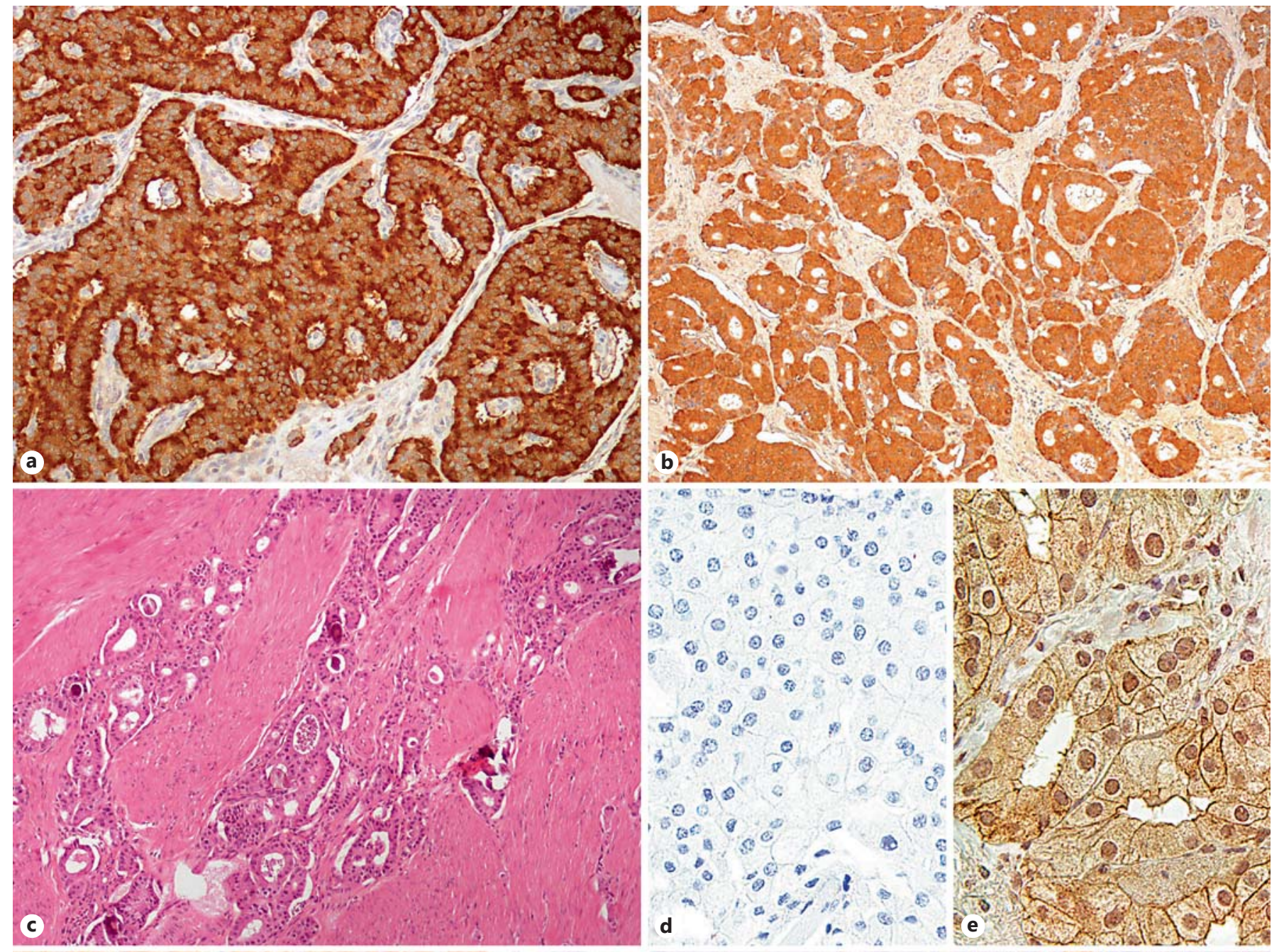

c
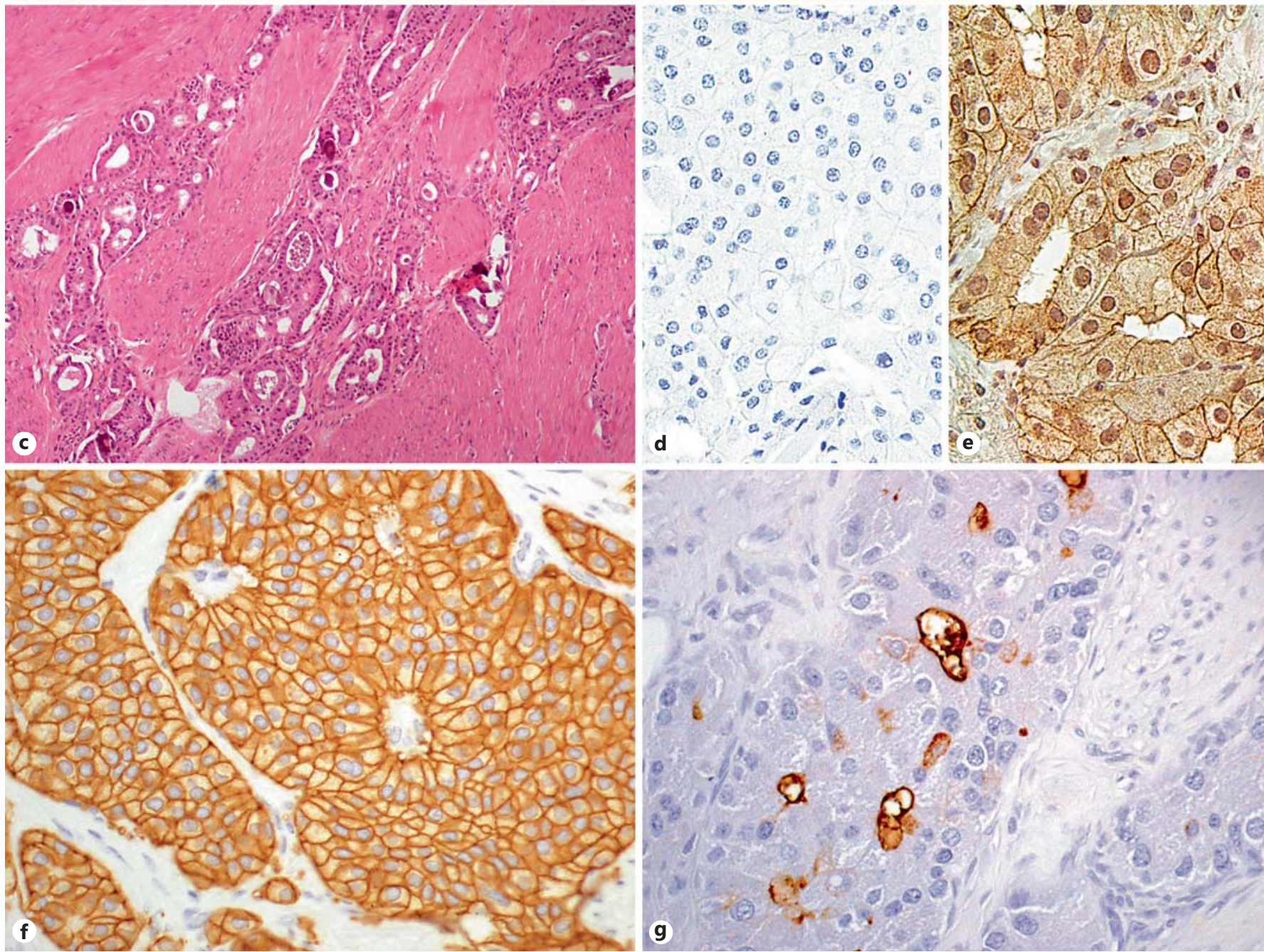


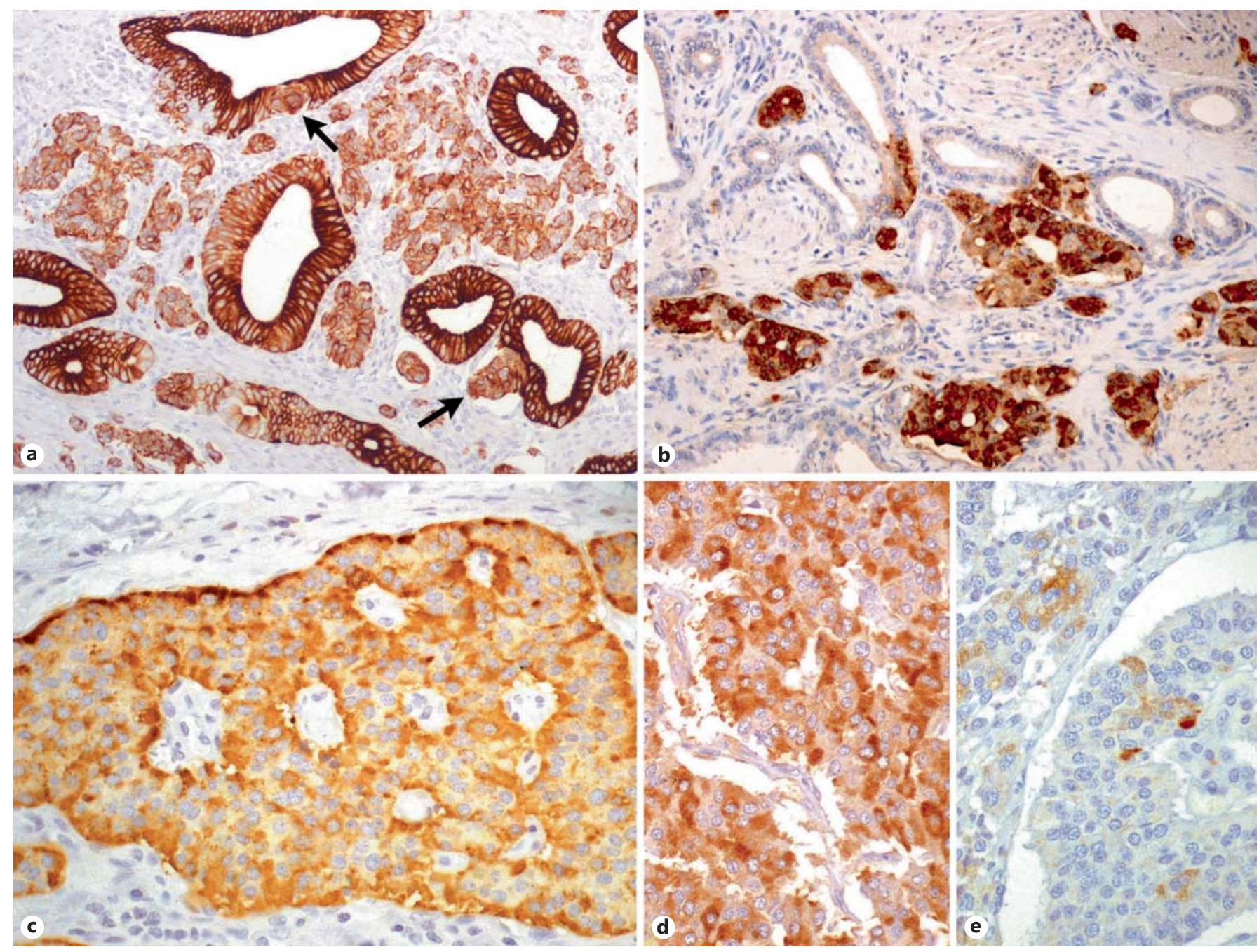

Fig. 3. a Cytokeratin 7 reactivity of ampullary epithelium (more weakly stained intraepithelial endocrine micronodules are marked by arrows) and AST tissue. $\times 200$. b Somatostatin-reactive endocrine cell neogenesis forming micronodules budding out of ampullary epithelium $(\mathbf{c}-\mathbf{e}) . \times 200$. Trabecular nfNET from the duodenal bulb showing chromogranin A $(\mathbf{c} ; \times 400)$, gastrin $(\mathbf{d} ; \times 400)$ and somatostatin $(\mathbf{e} ; \times 400)$ cells.

num; they were small, grade 1 (82\%), mucosal-submucosal tumors with a trabecular or microlobular structure. These tumors were often found incidentally at endoscopy or, at surgery, in gastroduodenal specimens resected for other diseases. In addition to these usually self-limited tumors, a few $(\mathrm{n}=18)$ cases were larger $(2 \mathrm{~cm}$ or more $)$, locally symptomatic and often grade $2(9 / 18)$, with a higher potential for deep wall or lymphovascular invasion and LN metastases ( $10 / 18$ vs. $9 / 87$ less than $2 \mathrm{~cm}, \mathrm{p}=0.003$ ), and they were observed in the various duodenal tracts. Among these latter tumors, 2 cases showed diffuse reactivity for serotonin (in the absence of the carcinoid syn- drome) and with solid nest structure somewhat mimicking that of serotonin-producing argentaffin (enterochromaffin) cell NETs commonly arising in the ileum and jejunum.

\section{Differences between NET Subtypes}

Comparative analysis between individual NET subtypes showed several important differences. In particular, when compared to ordinary nfNETs, ASTs were significantly ( $\mathrm{p}<0.001$ for all parameters) larger and more locally invasive in the duodenal wall beyond the submucosa, within lymphovascular vessels and LNs. Further- 
Table 3. Variables associated with local lymph node metastases in 194 neoplasms investigated

\begin{tabular}{|c|c|c|c|c|c|c|c|c|c|}
\hline & \multicolumn{3}{|c|}{ Whole series } & \multicolumn{3}{|c|}{ NETs only } & \multicolumn{3}{|c|}{ nfNETs only } \\
\hline & OR & $95 \% \mathrm{CI}$ & $\mathrm{p}$ value & OR & $95 \% \mathrm{CI}$ & $\mathrm{p}$ value & OR & $95 \% \mathrm{CI}$ & $\mathrm{p}$ value \\
\hline Proliferative grade & 4.02 & $2.62-6.18$ & $<0.001$ & & & $<0.001$ & & & $<0.001$ \\
\hline G2 vs. G1 & 4.88 & $2.20-10.83$ & $<0.001$ & 4.88 & $2.20-10.83$ & $<0.001$ & 4.96 & $2.17-11.33$ & $<0.001$ \\
\hline G3 vs. G1 & 13.06 & $5.47-31.18$ & $<0.001$ & & & & & & \\
\hline Lymphovascular invasion & 11.97 & $4.86-29.45$ & $<0.001$ & 9.36 & $3.33-26.32$ & $<0.001$ & 7.68 & $2.08-28.27$ & 0.002 \\
\hline Invasion beyond the submucosa & 6.99 & $2.70-18.00$ & $<0.001$ & 6.45 & $2.39-17.41$ & $<0.001$ & 20.72 & $6.53-65.69$ & $<0.001$ \\
\hline
\end{tabular}

OR $=$ Odds ratio.

Table 4. NET type optimal size cutoff and actual median size by lymph node metastatic status

\begin{tabular}{|c|c|c|c|c|c|c|c|c|c|}
\hline & \multicolumn{5}{|c|}{ Optimal size cutoff (ROC analysis) } & \multicolumn{4}{|c|}{ Size of cases with/without LN metastases } \\
\hline & \multirow{2}{*}{$\begin{array}{l}\text { available } \\
\text { cases }\end{array}$} & \multirow{2}{*}{$\begin{array}{l}\text { size, } \\
\mathrm{cm}\end{array}$} & \multirow{2}{*}{$\begin{array}{l}\text { sensitivity } \\
(95 \% \mathrm{CI})\end{array}$} & \multirow{2}{*}{$\begin{array}{l}\text { specificity } \\
(95 \% \mathrm{CI})\end{array}$} & \multirow{2}{*}{$\begin{array}{l}\text { AUC ROC } \\
(95 \% \mathrm{CI})\end{array}$} & \multicolumn{2}{|c|}{ without metastases } & \multicolumn{2}{|c|}{ with metastases } \\
\hline & & & & & & $\mathrm{n}$ & size, $\mathrm{cm}^{\mathrm{a}}$ & $\mathrm{n}$ & size, $\mathrm{cm}^{\mathrm{a}}$ \\
\hline GAS & 20 & 1 & $40 \%(12.2-73.8)$ & $80 \%(44.4-97.5)$ & $0.60(0.39-0.81)$ & 10 & $0.80(0.50-1)$ & 10 & $0.75(0.60-1.20)$ \\
\hline nfNET & 105 & 0.9 & $84 \%(60.4-96.6)$ & $73 \%(62.6-82.2)$ & $0.79(0.69-0.88)$ & 86 & $0.50(0.30-1)$ & 19 & $2.00(1.00-2.40)$ \\
\hline AST & 37 & 2 & $70 \%(45.7-88.1)$ & $71 \%(44-89.7)$ & $0.70(0.55-0.86)$ & 17 & $1.60(0.80-2.50)$ & 20 & $2.50(2-3.20)$ \\
\hline NET & $175^{\mathrm{b}}$ & 1.1 & $75 \%(61.1-86)$ & $70 \%(61-77.9)$ & $0.72(0.65-0.80)$ & 123 & $0.70(0.30-1.30)$ & 52 & $2.00(1.10-2.00)$ \\
\hline
\end{tabular}

AUC $=$ Area under the curve; GAS = gastrinoma. ${ }^{a}$ Median size (interquartile range). ${ }^{\mathrm{b}}$ Gangliocytic paragangliomas and insulinoma included.

more, median patient age was younger and a clear preferential location in the ampullary region (vs. proximal duodenum) was seen for ASTs (tables 1, 2). Gastrinomas also differed from nfNETs in showing younger patient age $(\mathrm{p}=0.001)$ and more $\mathrm{LN}$ involvement $(\mathrm{p}=0.007)$ despite their overlapping median size, topography and histological structure. GPs differed from nfNETs in size $(\mathrm{p}<0.001)$ and preferential site (ampullary region vs. proximal duodenum).

In the whole NEN series, as well as among NETs or nfNETs alone, proliferative index grade 2 or 3, lymphovascular invasion and invasion beyond submucosa all proved to be highly associated with local LN metastases (table 3). Among NET subtypes, both ASTs and gastrinomas were significantly more associated than nfNETs with LN metastases (table 2). The relationship between tumor size and LN metastases among NETs and NET subtypes is further analyzed in table 4 , where the empirically determined optimal size cutoff for ASTs turned out to be substantially higher than those of gastrinomas, nfNETs and NETs as a whole. However, nfNETs sharply differed from gastrinomas in showing a median size of metastatic cases four times larger than that of nonmetastatic cases, whereas no size difference was found between metastatic and nonmetastatic gastrinomas. Indeed, among nfNETs, size was highly significantly $(\mathrm{p}<0.001)$ associated with LN metastases. On the other hand, size was only moderately $(\mathrm{p}=0.017)$ associated with metastases for ASTs and showed no association $(\mathrm{p}=0.65)$ for gastrinomas. Only $13 / 176(7 \%)$ NETs had distant metastases, mostly to the liver, at diagnosis. Of these, 8 were nfNETs, 3 ASTs and 2 gastrinomas, without significant subtype difference.

\section{Disease-Specific Survival}

One hundred and ninety patients had a median follow-up of 108 months (25th-75th: 50-181). Disease-specific survival analysis observed 33 disease-related deaths, $23 / 27$ in the NEC group and 10/163 in the NET group. Further subtype analysis revealed disease-related deaths in 3/36 ASTs, 4/95 nfNETs, 2/20 gastrinomas and 1/12 GPs. NECs caused patient death in a median of 10 months (25th-75th: 5-18) time, with only 1 patient alive without disease 42 months after surgery, 2 dead after 1 and 30 months, respectively, from other causes and 1 surviving 
Table 5. Disease-specific survival of the whole series (190 cases followed)

\begin{tabular}{|c|c|c|c|c|c|c|}
\hline & \multicolumn{3}{|c|}{ Univariable analysis } & \multicolumn{3}{|c|}{ Multivariable analysis ${ }^{\mathrm{a}}$} \\
\hline & HR & $95 \% \mathrm{CI}$ & $\mathrm{p}$ value & HR & $95 \% \mathrm{CI}$ & $\mathrm{p}$ value \\
\hline \multicolumn{7}{|l|}{ Size } \\
\hline As continuous variable & 1.60 & $1.34-1.91$ & $<0.001$ & 1.20 & $1.05-1.38$ & 0.008 \\
\hline Size $>1.1 \mathrm{~cm}$ & 9.27 & $2.75-31.28$ & $<0.001$ & 2.25 & $0.73-6.95$ & 0.160 \\
\hline Size $\geq 2 \mathrm{~cm}$ & 7.00 & $3.61-13.58$ & $<0.001$ & 2.13 & $1.08-4.23$ & 0.03 \\
\hline Proliferative grade & & & $<0.001$ & & & $<0.001$ \\
\hline G2 vs. G1 & 6.39 & $1.36-29.97$ & 0.012 & 3.21 & $0.62-16.46$ & 0.261 \\
\hline G3 vs. G1 & 88.90 & $22.26-355.00$ & $<0.001$ & 27.83 & $4.70-164.90$ & $<0.001$ \\
\hline G3 vs. G2 & 13.92 & $4.21-46.00$ & $<0.001$ & 8.66 & $2.98-25.18$ & $<0.001$ \\
\hline G3 (NECs) vs. G1 + 2 (NETs) & 43.48 & $28.57-66.67$ & $<0.001$ & 15.38 & $7.25-32.26$ & $<0.001$ \\
\hline Lymphovascular invasion & 12.50 & $4.20-37.24$ & $<0.001$ & 5.16 & $1.80-14.83$ & 0.002 \\
\hline Invasion beyond the submucosa & 9.29 & $3.49-24.67$ & $<0.001$ & 3.04 & $0.81-11.38$ & 0.100 \\
\hline Stage III-IV vs. I-II & 23.31 & $4.05-135.35$ & $<0.001$ & - & - & - \\
\hline
\end{tabular}

with disease after 23 months. Interestingly, the longest survivor (72 months) showed DNA microsatellite instability (see the duodenal case in Sahnane et al. [17]). NECs showed worse disease-specific survival compared to NETs as a whole or to each one of the subtypes or even to the 36 grade 2 NETs (table 5; fig. 4). In fact, of the 5 NEN types, only NECs significantly predicted patient survival (e.g. HR 31.47, 10.31-96.10, p < 0.001 vs. ASTs). Among the whole series, size, proliferative grade 2 and 3 , lymphovascular invasion, invasion beyond submucosa, stage III and IV were significantly related to worse survival (table 5). The same parameters, with the exception of stage III, proved predictive also among NETs alone and nfNETs alone. At multivariable analysis, grade 3 NECs, lymphovascular invasion, size as continuous variable and size $\geq 2 \mathrm{~cm}$ (but not size $>1.1 \mathrm{~cm}$ ) remained significant.

\section{Advanced NETs}

To improve analysis of NETs developing distant metastases at any time during their history (nonlocal tumors), we pooled cases with distant metastases at diagnosis (13 cases; a) with those dead from recurrent disease with distant metastases during follow-up (6 additional cases; b) and those alive with recurrent disease and distant metastases (4 additional cases; c). In all, 23 advanced (nonlocal) NETs were collected which, when compared to 143 cases with local disease throughout the study, showed, at the time of first diagnosis, significant differences ( $p<0.001$ for all variables) in mean size $(2.23 \pm 1.24$ vs. $1.19 \pm 1.03)$, proliferative grade $2(12 / 23,52 \%$ vs. $23 / 143,16 \%)$, lymphovascular invasion $(19 / 23,83 \%$ vs. $40 / 136,29 \%)$, deep wall invasion $(16 / 22,73 \%$ vs. $46 / 139$, $33 \%)$ and LN metastatic rate $(18 / 23,78 \%$ vs. $32 / 142$, $23 \%)$. They included $8 / 37$ (22\%) ASTs, $4 / 20$ (20\%) gastrinomas, 10/96 (10\%) nfNETs and 1/12 (8\%) GP, with no significant differences between subtypes. However, when tumors $<$ or $\geq 2 \mathrm{~cm}$ in size were compared, 15 out of 48 (31\%) NETs $\geq 2 \mathrm{~cm}$ were nonlocal versus 8 out of 117 $<2 \mathrm{~cm}(7 \%)$ NETs $(\mathrm{p}<0.001)$. When evaluation was restricted to nfNETs, 8 out of 17 tumors $(47 \%) \geq 2 \mathrm{~cm}$ versus 2 out of $78(2.6 \%)$ nfNETs $<2 \mathrm{~cm}(\mathrm{p}<0.001)$ proved to be nonlocal. Moreover, none of the $58 \mathrm{nfNETs}<1 \mathrm{~cm}$ in size progressed to nonlocal disease, versus 10 out of 37 tumors $\geq 1 \mathrm{~cm}$. Thus, the metastatic power of individual nfNETs seems to be strongly size dependent.

\section{Endoscopically Removed NETs}

Of 51 endoscopically removed NETs available for detailed analysis, 41 proved to be nfNETs, 3 ASTs, 2 GPs and 1 gastrinoma. Forty-one (median size $0.4 \mathrm{~cm}$ ) were from the duodenal bulb, 6 (median size $0.3 \mathrm{~cm}$ ) from the second duodenal tract and 4 (median size $1.1 \mathrm{~cm}$ ) from the ampullary region. Overall, only 4 cases showed proliferative grade 2, 2 out of 49 exhibited lymphovascular invasion and none had invasion beyond the submucosa. During a median follow-up of 114 (25th-75th: 48-185) months, only a single case (an ampullary AST) developed liver metastases, and no LN metastases were demonstrated. 


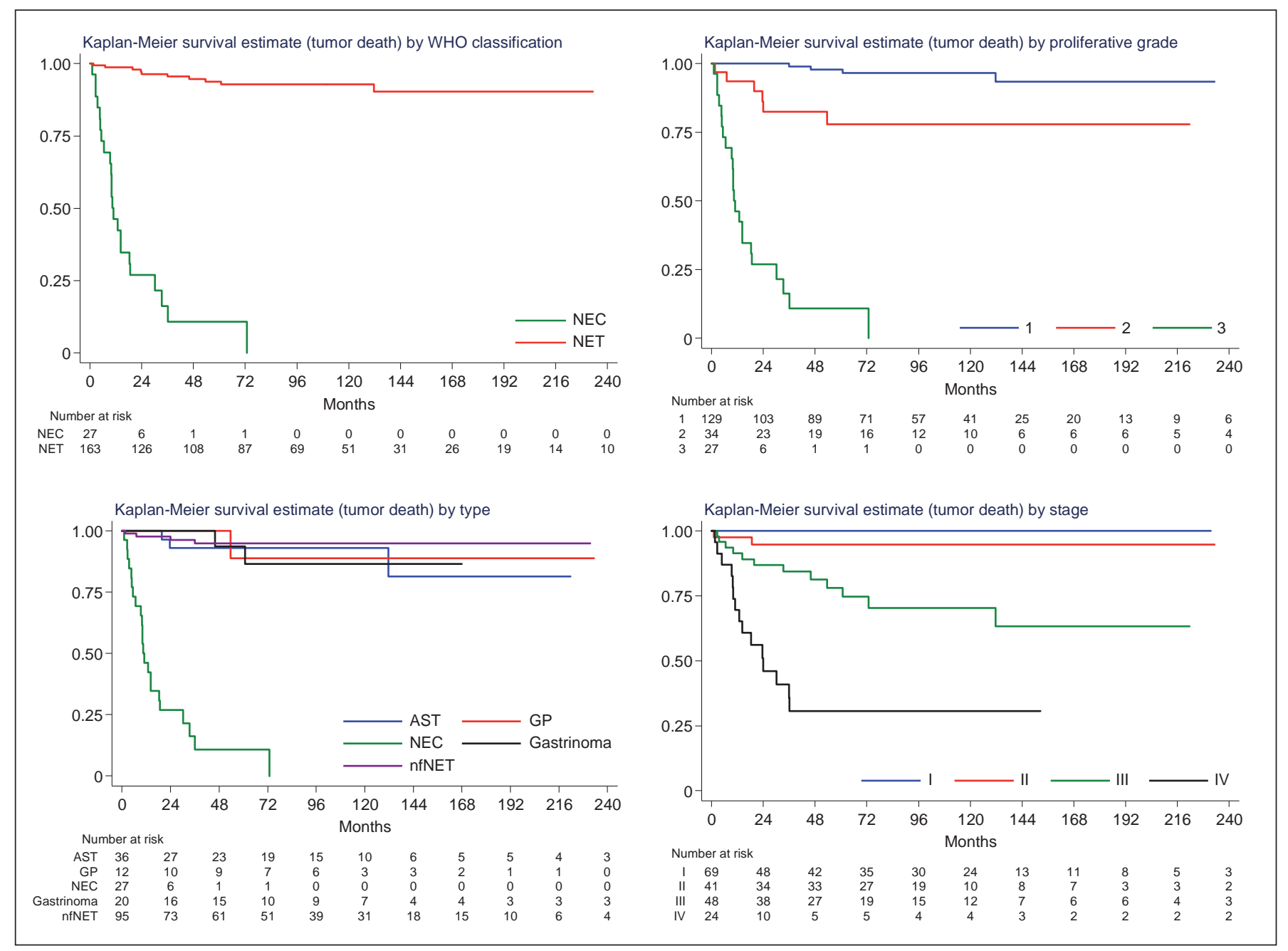

Fig. 4. Kaplan-Meier disease-specific survival estimates for the whole series of duodenal NENs, by the WHO classification (NEC vs. NET), proliferative grade, type and stage.

\section{Discussion}

In this study, five types of NENs with distinctive clinicopathological profiles were identified among more than 200 neoplasms arising in the duodenal tract. The neoplasms were first classified, based on both the histopathological pattern and proliferative index $[10,12,14]$, as grade 1 or 2 NETs and grade 3 NECs. All NECs had $>20 \%$ Ki67 index or $>20$ mitoses/10 HPFs or both, and showed poorly differentiated histology. Our findings confirm the concentration of NECs in the ampullary region $[8,9]$, add a few duodenal wall NECs not related to the ampulla and outline marked behavioral differences of NECs compared to duodenal NETs. Indeed, disease-specific survival anal- ysis showed clearly worse behavior of NECs compared with NETs as a whole or even with grade 1 or 2 NETs separately. In particular, most NECs (23/27) led to patient demise in a median of 10 months from diagnosis, while very few (10/163 cases) NETs caused patient death and often after prolonged survival with ongoing metastatic disease.

A combination of histological, histochemical and functional criteria has identified four NET subtypes: the GP, the hyperfunctioning NET (several gastrinomas and a single insulinoma case), the AST and ordinary nfNET. These subtypes turned out to show distinct topographic distribution, natural history and, to some extent, prognosis. 
In accordance with an investigation by Rosentraeger et al. [18] (published online after this study was completed), no histological/histochemical difference was found between gastrin-expressing neoplasms with or without associated endocrine hyperfunction syndrome, nor did tumor mass account for their different functional behavior. Indeed, active gastrinomas, especially those multicentrically arising in a background of MEN1, were among the smallest duodenal NETs $[4,5]$. Although active duodenal gastrinomas usually showed exclusive, or largely predominant, gastrin cells at the histochemical level, we also found plenty of endocrinally silent tumors rich in gastrin cells, with or without associated somatostatin and/or other cells. The cellular and molecular mechanisms causing tumor endocrine hyperfunction and its clinical relevance remain largely unknown. Gastrinomas are best considered separately from clinically nonfunctioning NETs, as the gastrinoma syndrome can, by itself, dominate the clinical picture, thus becoming the main therapeutic issue $[5,19,20]$. Furthermore, gastrinomas have a selective association with MEN1 syndrome as well as a higher frequency of LN metastases, sometimes from occult primaries, either in the duodenum or in the uppermost jejunum $[4,5]$. On the other hand, the strong size dependence of nfNETs' LN metastatic power is noteworthy as it recalls the large population of functionally uncharacterized 'indolent' NETs recruited in the SEER tumor registry, mostly small in size, stage I and with excellent outcome [21]. Incidentally diagnosed cases at endoscopy are likely to contribute significantly to this population, which in our series was mostly concentrated in the proximal duodenum and essentially uneventful during a prolonged follow-up.

ASTs were characterized by diffuse somatostatin reactivity of fairly large cells, by the presence of tubuloacinar structures with or without luminal psammoma bodies, and by their lack of reactivity for type $2 \mathrm{~A}$ somatostatin receptors, coupled with reactivity for type 5 receptors. This pattern, together with their mostly ampullary/periampullary location, separated ASTs from usually trabecular or microlobular ordinary nfNETs, even when the latter contained a somatostatin cell component. This study confirmed the presence of sparse somatostatin cells in normal ampullary-papillary epithelium $[4,22]$. In addition, in several AST cases, apparently newly formed, dysplastic somatostatin cell cords and micronodules, sometimes budding out from the ampullary/papillary epithelium and infiltrating the adjacent stroma were seen. These findings, which reproduced in part previous observations on NET histogenesis in the duodenal $[23,24]$ and gastric

Duodenal Neuroendocrine Neoplasms mucosa [25], raise the issue of a direct histogenetic link of at least some ASTs with the ampullary-papillary epithelium.

Although none of our AST cases showed unequivocal signs of somatostatin-related endocrine hyperfunction relieved by tumor excision, these findings (particularly diabetic ketoacidosis) have been reported by others [2628]. Another point of potential clinical interest is AST's frequent lack of type $2 \mathrm{~A}$ somatostatin receptors, coupled with the intense expression of type 5 receptors, which may have implications for the choice of appropriate somatostatin analogue therapy $[29,30]$. These observations further support the need to separate ASTs from ordinary nfNETs, as strongly suggested by their differences in histopathological, histochemical and topographic features and in invasive potential.

Although GPs have been commonly reported as 'benign' or self-limiting growths, we found 3 metastatic cases to local LNs out of 12 investigated, one of which proved fatal owing to tumor recurrence and progression after surgery. At least 20 other GPs metastatic to local LNs and a single fatal case have also been reported in the literature $[31,32]$. Thus, a limited, low-grade malignant potential should be attributed to such tumors, despite the usually excellent outcome of most reported cases, including 11 of our 12 cases ( 2 of which were locally metastatic, however). As a rule, $\mathrm{PP}$ immunoreactivity was prominent among paraganglioid cells, as found in 8 of 9 GPs tested, a finding at variance with the lack of reactivity for PP of 26 out of 28 ASTs tested. As outlined by Okubo et al. [33], this feature may help to distinguish the two tumors despite their common reactivity for somatostatin and preference for the ampullary-periampullary region. The identification of gangliocytic and spindle cell components (in addition to paraganglioid cells) within metastatic GP tissue speaks for a neoplastic origin of these cells and effectively rules out a merely reactive role of such components.

NET size, site, proliferative grade 2 and locally invasive pattern were shown to strongly correlate with local LN metastatic rate, although they had limited influence on disease-specific patient survival, which, as confirmed by multivariable analysis, was mainly influenced by grade 3 NEC status and stage IV (distant metastases). However, the long-term follow-up of NETs suggests that, notwithstanding their slowly invasive growth, late distant metastases may be seen in a few patients, especially with ASTs, and may be the cause of death. In the large population of nfNETs, only those $\geq 2 \mathrm{~cm}$ in size seemed to be at consistent risk of both local LN and distant metastases, while those $<1 \mathrm{~cm}$ seemed to carry a negligible risk. On the oth- 
er hand, ASTs and gastrinomas are at higher risk of local LN metastases, a risk which, at variance with nfNETs, is not influenced by tumor size in gastrinomas.

In spite of the fact that the four NET subtypes display significant differences in variables with potential prognostic impact, the disease-specific survival analysis did not show statistically significant differences between the four NET subtypes. It is possible that differences could be appreciated for progression-free survival only. However, the present series lacked some pertinent data and, for some subtypes, such as GP and gastrinoma, also lacked the numbers required to reach statistically meaningful conclusions. Larger studies gathering multiple cases of these rare entities from multiple institutions on a larger scale are needed to answer such questions.

Finally, though the involvement of several Pathology Centers with long referral experience in the field was a guarantee of data quality, the present multicenter study has several limitations, the most important being its inherently retrospective nature. This may imply significant differences in data collection, overall patient manage- ment and therapy, features that all may have set data biases. Nonetheless, we believe that the identification of potentially informative histopathological parameters may help in designing prospective clinicopathological studies aiming to define solid criteria for alternative therapeutic choices, such as surgery or endoscopic excision [34, 35].

\section{Acknowledgements}

This study was supported by Grants from the Italian Ministry of Health (grant No. RF-2010-2310098), from Fondazione Cariplo (grant No. 2012-0529) to Fondazione IRCCS Policlinico San Matteo and from Associazione Italiana Ricerca sul Cancro - AIRC IG 2013-14696 to G.R.

\section{Disclosure Statement}

G.R. declares that he has received consultant honoraria by Advanced Accelerator Applications SA, Bracco Imaging, Ipsen Pharma, and speaker's fee by Novartis Pharma and Ipsen Pharma. Other authors declare that they do not have any conflicts of interest.

\section{References}

-1 Dayal Y, Doos WG, O’Brien MJ, Nunnemacher G, DeLellis RA, Wolfe HJ: Psammomatous somatostatinomas of the duodenum. Am J Surg Pathol 1983;7:653-665.

$\checkmark 2$ Perrone T, Sibley RK, Rosai J: Duodenal gangliocytic paraganglioma. An immunohistochemical and ultrastructural study and a hypothesis concerning its origin. Am J Surg Pathol 1985;9:31-41.

-3 Burke AP, Sobin LH, Federspiel BH, Shekitka KM, Helwig EB: Carcinoid tumors of the duodenum. A clinicopathologic study of 99 cases. Arch Pathol Lab Med 1990;114:700-704.

-4 Capella C, Riva C, Rindi G, Sessa F, Usellini L, Chiaravalli AM, Carnevali L, Solcia E: Histopathology, hormone products, and clinicopathological profile of endocrine tumors of the upper small intestine: a study of 44 cases. Endocr Pathol 1991;2:92-110.

5 Anlauf M, Garbrecht N, Henopp T, Schmitt A, Schlenger R, Raffel A, Krausch M, Gimm $\mathrm{O}$, Eisenberger CF, Knoefel WT, Dralle H, Komminoth P, Heitz PU, Perren A, Klöppel G: Sporadic versus hereditary gastrinomas of the duodenum and pancreas: distinct clinicopathological and epidemiological features. World J Gastroenterol 2006;12:5440-5446.

6 Garbrecht N, Anlauf M, Schmitt A, Henopp T, Sipos B, Raffel A, Eisenberger CF, Knoefel WT, Pavel M, Fottner C, Musholt TJ, Rinke A, Arnold R, Berndt U, Plöckinger U, Wiedenmann B, Moch H, Heitz PU, Komminoth P, Perren A, Klöppel G: Somatostatin-pro- ducing neuroendocrine tumors of the duodenum and pancreas: incidence, types, biological behavior, association with inherited syndromes, and functional activity. Endocr Relat Cancer 2008; 15:229-241.

7 Untch BR, Bonner KP, Roggin KK, Reidy-Lagunes D, Klimstra DS, Schattner MA, Fong Y, Allen PJ, D’Angelica MI, DeMatteo RP, Jarnagin WR, Kingham TP, Tang LH: Pathologic grade and tumor size are associated with recurrence-free survival in patients with duodenal neuroendocrine tumors. J Gastrointest Surg 2014;18:457-462; discussion 462-463.

$>8$ Zamboni G, Franzin G, Bonetti F, Scarpa A, Chilosi M, Colombari R, Menestrina F, Pea M, Iacono C, Serio G, et al: Small-cell neuroendocrine carcinoma of the ampullary region. A clinicopathologic, immunohistochemical, and ultrastructural study of three cases. Am J Surg Pathol 1990;14:703-713.

-9 Nassar H, Albores-Saavedra J, Klimstra DS: High-grade neuroendocrine carcinoma of the ampulla of Vater: a clinicopathologic and immunohistochemical analysis of 14 cases. Am J Surg Pathol 2005;29:588-594.

10 Rindi G, Arnold R, Bosman FT, Capella C, Klimstra DS, Kloppel G, Komminoth P, Solcia E: Nomenclature and classification of neuroendocrine neoplasms of the digestive system; in Bosman FT, Carneiro F, Hruban RH, Theise ND (eds): WHO Classification of Tumours of the Digestive System. Lyon, IARC Press, 2010, pp 13-14.
11 Edge SB, Byrd DR, Compton CC, Fritz AG, Greene FL, Trotti A (eds): AJCC Cancer Staging Manual. New York, Springer, 2009.

12 Rindi G, Klöppel G, Alhman H, Caplin M, Couvelard A, de Herder WW, Erikssson B, Falchetti A, Falconi M, Komminoth P, Körner M, Lopes JM, McNicol AM, Nilsson O, Perren A, Scarpa A, Scoazec JY, Wiedenmann B; all other Frascati Consensus Conference participants; European Neuroendocrine Tumor Society (ENETS): TNM staging of foregut (neuro)endocrine tumors: a consensus proposal including a grading system. Virchows Arch 2006;449:395-401.

13 Volante M, Brizzi MP, Faggiano A, La Rosa S, Rapa I, Ferrero A, Mansueto G, Righi L, Garancini S, Capella C, De Rosa G, Dogliotti L, Colao A, Papotti M: Somatostatin receptor type 2A immunohistochemistry in neuroendocrine tumors: a proposal of scoring system correlated with somatostatin receptor scintigraphy. Mod Pathol 2007;20:1172-1182.

14 Rindi G, Azzoni C, La Rosa S, Klersy C, Paolotti D, Rappel S, Stolte M, Capella C, Bordi C, Solcia E: ECL cell tumor and poorly differentiated endocrine carcinoma of the stomach: prognostic evaluation by pathological analysis. Gastroenterology 1999;116:532542 .

15 Rindi G, Petrone G, Inzani F: The 2010 WHO classification of digestive neuroendocrine neoplasms: a critical appraisal four years after its introduction. Endocr Pathol 2014;25:186-192. 
-16 La Rosa S, Pariani D, Calandra C, Marando A, Sessa F, Cortese F, Capella C: Ectopic duodenal insulinoma: a very rare and challenging tumor type. Description of a case and review of the literature. Endocr Pathol 2013;24:213219.

17 Sahnane N, Furlan D, Monti M, Romualdi C, Vanoli A, Vicari E, Solcia E, Capella C, Sessa F, La Rosa S: Microsatellite unstable gastrointestinal neuroendocrine carcinomas: a new clinicopathologic entity. Endocr Relat Cancer 2015;22:35-45.

18 Rosentraeger MJ, Garbrecht N, Anlauf M, Raffel A, Knoefel WT, Wiedenmann B, Klöppel G: Syndromic versus non-syndromic sporadic gastrin-producing neuroendocrine tumors of the duodenum: comparison of pathological features and biological behavior. Virchows Arch 2015, Epub ahead of print.

19 Donow C, Pipeleers-Marichal M, Schröder S, Stamm B, Heitz PU, Klöppel G: Surgical pathology of gastrinoma. Site, size, multicentricity, association with multiple endocrine neoplasia type 1 , and malignancy. Cancer 1991;68:1329-1334.

-20 Weber HC, Venzon DJ, Lin JT, Fishbein VA, Orbuch M, Strader DB, Gibril F, Metz DC, Fraker DL, Norton JA, Jensen RT: Determinants of metastatic rate and survival in patients with Zollinger-Ellison syndrome: a prospective long-term study. Gastroenterology 1995; 108:1637-1649.

-21 Fitzgerald TL, Dennis SO, Kachare SD, Vohra NA, Zervos EE: Increasing incidence of duodenal neuroendocrine tumors: incidental discovery of indolent disease? Surgery 2015; 158 : 466-471.
22 Dancygier H, Klein U, Leuschner U, Hübner $\mathrm{K}$, Classen M: Somatostatin-containing cells in the extrahepatic biliary tract of humans. Gastroenterology 1984;86:892-896.

23 Noda Y, Watanabe H, Iwafuchi M, Furuta K, Ishihara N, Satoh M, Ajioka Y: Carcinoids and endocrine cell micronests of the minor and major duodenal papillae. Their incidence and characteristics. Cancer 1992;70:18251833.

24 Anlauf M, Perren A, Meyer CL, Schmid S, Saremaslani P, Kruse ML, Weihe E, Komminoth P, Heitz PU, Klöppel G: Precursor lesions in patients with multiple endocrine neoplasia type 1-associated duodenal gastrinomas. Gastroenterology 2005;128:1187-1198.

25 Vanoli A, La Rosa S, Luinetti O, Klersy C, Manca R, Alvisi C, Rossi S, Trespi E, Zangrandi A, Sessa F, Capella C, Solcia E: Histologic changes in type A chronic atrophic gastritis indicating increased risk of neuroendocrine tumor development: the predictive role of dysplastic and severely hyperplastic enterochromaffin-like cell lesions. Hum Pathol 2013;44:1827-1837.

26 Kimura R, Hayashi Y, Takeuchi T, Shimizu M, Hiratsuka M, Yoshida M, Hamajima E, Iwata $M$, Imoto $M$, Hattori H: Large duodenal somatostatinoma in the third portion associated with severe glucose intolerance. Intern Med 2004;43:704-707.

27 Nesi G, Marcucci T, Rubio CA, Brandi ML, Tonelli F: Somatostatinoma: clinico-pathological features of three cases and literature reviewed. J Gastroenterol Hepatol 2008;23: 521-526.
28 Engelund Luna I, Monrad N, Binderup T, Boisen Thoegersen C, Hilsted L, Jensen C, Federspiel B, Knigge U: Somatostatin immunoreactive pancreatico-duodenal neuroendocrine neoplasms: twenty-three cases evaluated according to the WHO 2010 Classification. Neuroendocrinology 2015, Epub ahead of print.

29 McKeage K: Pasireotide: a review of its use in Cushing's disease. Drugs 2013;73:563-574.

30 Cives M, Strosberg J: The expanding role of somatostatin analogs in gastroenteropancreatic and lung neuroendocrine tumors. Drugs 2015;75:847-858.

31 Shi H, Han J, Liu N, Ye Z, Li Z, Li Z, Peng T: A gangliocytic patially glandular paraganglioma with lymph node metastasis. Diagn Pathol 2014;9:63.

32 Li B, Li Y, Tian XY, Luo BN, Li Z: Malignant gangliocytic paraganglioma of the duodenum with distant metastases and a lethal course. World J Gastroenterol 2014;20:15454-15461.

33 Okubo Y, Nemoto T, Wakayama M, Tochigi N, Shinozaki M, Ishiwatari T, Aki K, Tsuchiya M, Aoyama H, Katsura K, Fujii T, Nishigami T, Yokose T, Ohkura Y, Shibuya K: Gangliocytic paraganglioma: a multi-institutional retrospective study in Japan. BMC Cancer 2015; 15:269.

34 Petrone G, Ricci R, Familiari P, Inzani F, Matsuoka M, Mutignani M, Delle Fave G, Costamagna G, Rindi G: Endoscopic snare papillectomy: a possible radical treatment for a subgroup of T1 ampullary adenocarcinomas. Endoscopy 2013;45:401-404.

35 Kachare SD, Liner KR, Vohra NA, Zervos EE Fitzgerald TL: A modified duodenal neuroendocrine tumor staging schema better defines the risk of lymph node metastasis and diseasefree survival. Am Surg 2014;80:821-826. 